\title{
An Empirical Test of An Analytical Framework for Evaluation of Different Corporate-Startup Collaboration Models
}

\author{
Annika Steiber ${ }^{*}$, Sverker Alänge ${ }^{2}$
}

\begin{abstract}
Rapid technological developments make firms favor the creation of new approaches to corporate entrepreneurship and technology management. One approach, corporate-startup collaboration has reached a new level in the 21st Century and many different models currently exist as a result. However, research on how to evaluate the effects of those collaboration models is limited, and in some cases, non-existent. The purpose of this paper is to test if an analytical framework developed for measuring the results from corporate-startup co-location, also could be useful for measuring the results of other types of corporate-startup collaboration models. The framework is tested through the lens of the corporation and the collaboration unit. The empirical study includes 10 cases, representing five different corporate-startup models. The finding was that the analytical framework is useful in planning, analyzing and follow- up the results of many different corporate-startup collaboration models.
\end{abstract}

Keywords: startup; collaboration; open innovation; analytical framework; corporate-startup collaboration models.

Submitted: August $26^{\text {th }}, 2020 /$ Approved: $15^{\text {th }}, 2020$

\section{Introduction}

Rapid technological development creates a tremendous pressure on incumbents to radically change the way they are organizing their innovation processes, if they will have a chance of surviving and prospering (March, 1991; Christensen \& Overdorf, 2000; Badescu \& GarcésAyerbee, 2009; Lee et al., 2012). This drives the creation and diffusion of new types of entrepreneurship (Oukil, 2011; Nambisan, 2017), affecting large firms to change their approach to corporate entrepreneurship. Therefore, as a complement to internal R\&D, high technology strategic alliances can offer large firms access to technologies (Clauss \& Spieth, 2017; Roth et al., 2017; Aggarwal \& Kapoor, 2018). Corporatestartup collaboration, as one form of strategic alliances, is increasingly becoming an attractive strategy (Weiblen \& Chesbrough, 2015; Steiber \& Alänge, 2020). For this reason, many different models have been developed and applied by large firms (Steiber \& Alänge, 2020).

'Corporate-startup collaboration models' are here viewed as a management initiative, following an open innovation paradigm (Chesbrough, 2003) and an extensive amount of previous research exists on different models for corporate-startup collaboration. However, research on how to evaluate and measure the results from those different types of collaborations, is limited, and in some cases non-existent (Steiber \& Alänge, 2020).

The purpose of this paper is to test if an analytical framework, developed for measuring the results from corporate-startup co-location could also be useful for measuring the effects from other types of corporate-startup collaboration models.

The sections below start with a theoretical context that present main findings from earlier literature reviews on frameworks and metrics, followed by the methodology for the empirical study used for this paper. The paper ends with a discussion on how useful the analytical framework is for different types of corporate-startup collaboration models. Finally, conclusions, implications, as well as limitations and future research will be presented.

\section{Theoretical Context}

Chesbrough (2003) developed the open innovation concept from observations of inbound and outbound streams of technology at large firms. The fast technological development in most industries is now increasing the emphasis on startups' role in corporate innovation, as the strength of small technology startups is their ability to develop not only new product and process innovations rapidly and test them on 'early adopters' (Rogers, 1983), but also to develop entirely new business models. For large firms, technology startups can also allow the large firm to be part of the construction of totally new entrepreneurial ecosystems (Drori \& Wright, 2018).

\section{Models for corporate-startup collaboration}

Several different models for corporate-startup collaboration have been identified. Based on a several years long research study, Steiber \& Alänge (2020) identified and described eight models for corporatestartup collaboration: 1. Acquisition, 2. Corporate Venturing, 3. Internal Corporate Incubator, 4. Internal Corporate Accelerator, 5. Platform, 6. Corporate Startup Program, 7. Co-Creation and 8. Co-Location. The different models will be described below in accordance to the findings from Steiber \& Alänge (2020).

Acquisition and Corporate Venturing are models using an outside-in flow as well as an equity-based model. Acquisition is when the large firm acquires the startup. Corporate- venturing, is when the firm invest (rather than build or ally for new technologies) in external startups of strategic interest.

(1) Menlo College, Atherton, CA 94027, USA.

(2) Foundation IMIT, Sweden

Corresponding author: annika.steiber@menlo.edu

ISSN: 0718-2724. (http://jotmi.org)

Journal of Technology Management \& Innovation @ Universidad Alberto Hurtado, Facultad de Economía y Negocios. 
Models using an inside-out flow as well as an equity-based model are the third and fourth models; Internal Corporate Incubator and Internal Corporate Accelerator. In an internal corporate incubator, internal ideas may lead to spinout companies and in the internal accelerator program, cohorts of (here internal) idea providers are coached to take their ideas further.

Models using an inside-out flow as well as a non-equity-based model are platforms and corporate startup programs. By platforms it is meant a large firm's proprietary platform, e.g., Android or iOS. The 'Platform model' is an Inside-out approach in which the larger firm invites complementary external startup innovation to advance existing corporate innovation (the platform), but also to strengthen the large firm's ecosystem. The primary purpose of a Corporate Startup Program such as e.g. Google for Startups, is for the large firm to support entrepreneurs with access to the large firm's products, services, or other assets and thereby sustaining or even expanding the ecosystem around the large firm's products and services.

Finally, co-creation and co-location are models using an outside-in and non-equity-based model. Co-creation is a management initiative that brings different parties together in order to jointly produce a mutually valued outcome. Business co-location is the placement of several entities in a single location. In the context of co-location of tech startups close to a host corporation, co-location is a rather new phenomenon.

Based on the above information, knowledge currently exist on models for collaboration between corporations and startups. However, earlier research on these corporate-startup collaboration models has shown that there is very limited research on how to measure and evaluate each model's results in terms of e.g. financial gains and increased innovation rate for the corporation, as well as the success rate for the startup. In the last decade, when local governments have increased their investments in new corporate-startup collaboration initiatives, the effect on local ecosystems has also become an important factor to track (Steiber \& Alänge, 2020).

\section{The development of an analytical framework for corporate-startup co-location}

Earlier research on corporate-startup collaboration models has shown that there is very limited research on how to measure and evaluate each model's result. Further, research on co-creation and co-location has shown that knowledge on how to measure and evaluate these two models is more or less non-existent (Steiber, 2020). For this reason, Steiber (2020) decided to conduct an extensive literature review on the model 'corporate-startup co-location' with the purpose of developing an analytical framework for measuring and evaluating the result of this specific model.

A broader literature study on business co-location was therefore conducted on the phenomenon 'Business co-location'. Previous research on this phenomenon was found in five primary areas of research; 'cluster theories', 'ecosystem theories, network theories', theories on knowledge dissemination, as well as on corporate coworking (spaces). In total (60) abstracts from A and B rated scientific articles were selected. After a more thorough scanning of the 60 articles, 32 articles were finally selected and read to provide a better understanding of business co-location from five different perspectives (see Table 1 and literature stream).

Table 1. Selected articles, based on a literature review (Steiber, 2020)

\begin{tabular}{|c|c|c|}
\hline Article & Focus & Literature stream \\
\hline 1.Bamford \& Ernst, 2002 & Manage an Alliance portfolio & Economic theories \\
\hline 2.Bouncken et al., 2016 & Co-working spaces & Collaborative work- spaces and Co-working spaces \\
\hline 3.Cabral \& van Winden, 2016 & Categories of Co-working spaces & Collaborative work- spaces and Co-working spaces \\
\hline 4.Cabral \& van Winden, 2018 & Categories of Co-working spaces & Collaborative work- spaces and Co-working spaces \\
\hline 5.Chesbrough \& Rosenbloom (2002) & The role of a business model in a context of open innovation & Economic theories \\
\hline 6.Chesbrough, 2003 & Open innovation: A new paradigm & Economic theories \\
\hline 7.Chow \& Chan, 2008 & $\begin{array}{l}\text { Social networks and social trust' effects on organizational } \\
\text { knowledge sharing. }\end{array}$ & Learning and Knowledge- dissemination \\
\hline 8.Cooke, 2002 & Cluster theories and if location matters & Cluster theories \\
\hline 9.Gallini, 2002 & The economies of patents & Economic theories \\
\hline 10.Gallivan, 2008 & Balancing trust and control in virtual organizations & Network/Ecosystem theories \\
\hline 11.Gertler \& Levitte, 2005 & Network theory and knowledge flows & Network/Ecosystem theories \\
\hline 12.Holste \& Fields, 2010 & Trust and tacit knowledge sharing and use & Learning and Knowledge- dissemination \\
\hline 13.Inkpen \& Tsang, 2005 & Social capital, network and knowledge transfer & Learning and Knowledge- dissemination \\
\hline 14.Irving et al., 2020 & Co-working space & Collaborative work- spaces and Co-working spaces \\
\hline 15.Lemarié et al., 2001 & $\begin{array}{l}\text { Small business economics and the importance of geographical and } \\
\text { organizational proximity }\end{array}$ & Network/Ecosystem theories \\
\hline 16.McKelvey et al., 2003 & $\begin{array}{l}\text { Cluster theory and regional innovation systems and the importan- } \\
\text { ce of location }\end{array}$ & Cluster theories \\
\hline 17.Muegge, 2013 & $\begin{array}{l}\text { Platforms, communities and ecosystems and technology entrepre- } \\
\text { neurship }\end{array}$ & Network/Ecosystem theories \\
\hline
\end{tabular}




\begin{tabular}{l|l|l}
\hline 18.Nagy \& Lindsay, 2018 & Collaborative co-working spaces & Collaborative work- spaces and Co-working spaces \\
\hline 19.Nonaka, 1994 & Organizational knowledge creation & Learning and Knowledge- dissemination \\
\hline 20.Porter et al.,2005 & Institutional embeddedness of high-tech regions & Cluster theories \\
\hline 21.Robinson et al., 2007 & Clusters and networks in nanotechnology & Cluster theories \\
\hline 22.Romero \& Molina, 2011 & Collaborative networked organization and Knowledge dissemination & Network/Ecosystem theories \\
\hline 23.Simard and West, 2006 & $\begin{array}{l}\text { Open innovation and knowledge networks and geographic locus } \\
\text { of innovation }\end{array}$ & Learning and Knowledge- dissemination \\
\hline 24.Song et al., 2007 & $\begin{array}{l}\text { Knowledge dissemination and the importance of co-location of } \\
\text { resources }\end{array}$ & Learning and Knowledge- dissemination \\
\hline 25.Stuart \& Sorenson, 2003 & Geographical proximity and spatial heterogeneity & Cluster theories \\
\hline 26.Teece, 1986a & Transaction cost economics and the multinational enterprise & Economic theories \\
\hline 27.Teece, 1986 & Profiting from technological innovation & Economic theories \\
\hline 28.Teece, 1989 & Inter-organizational requirements on the innovation process & Economic theories \\
\hline 29.Valkokari et al., 2017 & Orchestrating innovation ecosystems & Network/Ecosystem theories \\
\hline 30.Vanhaverbeke, 2006 & Open innovation and inter-organizational networks & Network/Ecosystem theories \\
\hline 31.Yeung et al., 2006 & Collective bargaining power and cluster theory & Cluster theories \\
\hline 32.Zenun et al., 2007 & Project management and performance (team co-location) & Learning and Knowledge- dissemination \\
\hline
\end{tabular}

Through the broadened search for literature under the heading of 'business co-location', Steiber (2020) identified a number of insights on business co-location in the form of underlying objectives with co-location initiatives, results observed, as well as factors that could affect those results.

As a result, a three- dimensions framework was suggested. The three dimensions are; the 'stakeholder dimension', the 'performance dimension', and a time dimension (see Figure 1).

Figure. 1: Three- dimensions framework for corporate-startup co-location (Steiber, 2020)

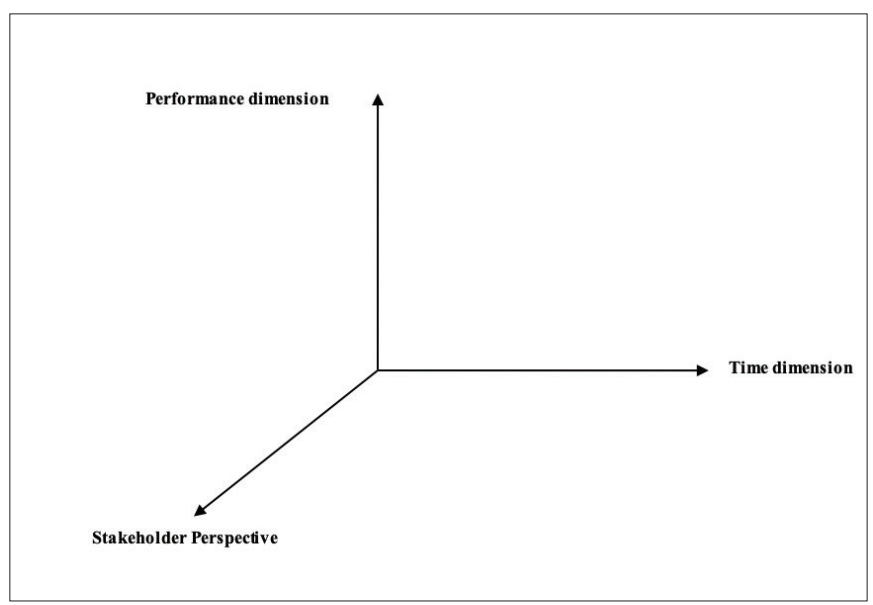

In the literature review, conducted by Steiber (2020), several different stakeholders were identified such as: the corporation, the unit for collaboration (e.g. an incubator), the startup, but also local governments and other public funding agencies, as well as universities and university incubators that at times work as a facilitator for establishing innovation collaboration between startups and incumbents.
For each stakeholder, the performance metrics differ. For example, for a corporation metrics are related to; return on investment, technology and innovation, customer relationship development, brand development, acquisition of new talent, corporate culture, and own ecosystem development. For a startup, however, metrics identified are; go-to-market relevant metrics as well as strategic business development metrics. From the perspective of the 'dyad' (the unit for collaboration) metrics are, process and result metrics focused on growth of the accelerator or incubator, economic results of the accelerator/incubator, and the performance of accelerated/incubated ventures. Finally, from an ecosystem perspective (usually represented by the local government), metrics related to the economic development of the region, such as: job creation, sustainability of local startups, innovations brought to industrial firms, and more have been identified in previous research.

Finally, regarding the 'time dimension', corporate-startup collaborations evolve over time and Steiber (2020) found that there was a need to add a dynamic dimension, labeled the 'time dimension'.

\section{Methodology: an empirical case study}

The analysis of the literature highlights a dearth of empirical, exploratory studies in the field of inter-organizational learning (Anand et al., in press). Consequently, we adopted an exploratory multiple case study approach (Danneels, 2002; Eisenhardt \& Graebner, 2007).

The empirical study for this paper was conducted from March to June 2020 and focused primarily on the perspectives of the corporate and the dyad (the unit for collaboration). In total 10 cases, representing five different models for corporate-startup collaboration were included in the empirical study. At the date of the interview, the authors had previous knowledge about the cases as the firms have been part of the authors' earlier empirical studies in 2017, 2018, and in 2019. 
As a consequence, the interview questions could primarily focus on the topic of the study, objectives behind their corporate-startup collaboration initiative, and frameworks and metrics applied by the companies used for the different models of corporate-startup collaboration. However, the interview also captured data on how the specific company's model has evolved over time.

The purpose was to test the analytical framework developed for corporate-startup co-location by Steiber (2020) and see if it could be useful also for other corporate-startup collaboration models.

The interviews were conducted with former or current leaders of the dyads, typically scheduled as 1.0 to 1.5 hours. Each interview was recorded and transcribed. The interview questionnaire was semi-structured and organized according to the three dimensions in figure 1. In those cases where the initiator of the dyad model was still actively involved in the dyad, the data provided a relevant perspective on the corporate objectives and metrics used at the time of the decision to establish the initiative. In several cases, the initiator on the dyad level had moved forward to other positions, or sometimes even to other companies - and then the data collected in the empirical study was based on the experience of the leaders that took over the programs, and their access to written documentation concerning the start.

Each interview started off with an introduction and clarification of the interviewee's role, responsibilities and the current status of the unit for collaboration (e.g. the primary role of the unit, processes and services offered, and number of startups engaged). As the authors have followed the evolution of the different dyads, recent changes of the unit were also discussed. Second, the discussion was narrowed down to the framework, which was shown to the interviewee over zoom. The framework was explained by the authors, and overall feedback from the interviewee was collected. Third, the interviewers used the semi-structured questionnaire and asked the interviewee to describe from his/her perspective what objectives and metrics had been used/were used at the start of the initiative, currently used, and will be used at any major evaluation of the initiative in the future (the time dimensions was therefore used first among the three dimensions). Then the interviewers asked the interviewee to go more in details on each metric and why it had been/was used. In this discussion, not only the purpose with the metrics became clear but also for what stakeholder it was for. For example, several of the units for collaboration also measured things that were important for the success of the startup. Further, as several of the initiatives were funded by the local government, they also measured things that they needed to report to the government in annual, or final reports.

\section{Results from the empirical study}

In the empirical study the analytical framework for corporate-startup co-location was tested on several different corporate-startup collaboration models.

All in all, 10 corporate-startup collaboration initiatives were interviewed: BioVentureHub (AstraZeneca), SynerLeap powered by ABB (shortly referred here as SynerLeap), TestaCenter (Cytiva, former GE HealthCare), Electrolux Open Innovation, Ericsson Garage in Gothenburg, Ericsson One in Stockholm, The Greenhouse (Lantmännen), Stena New Ventures, Stena Recycling Lab, and CampX (Volvo Group). Together, they represent five of the models presented in Steiber \& Alänge (2020): Co-location, Co-creation, Internal Corporate Accelerator, Internal Corporate Incubator, and Corporate Venture.

The starting point for three of the cases (Ericsson Garage, Ericsson One and the Greenhouse) was an ambition to primarily create conditions for internal idea providers to develop their ideas, i.e. inside-out models (Weiblen \& Chesbrough, 2015). However, these three cases, all later on decided to also invite external entrepreneurs and startups to further stimulate their intrapreneurs. Five of the cases started from an outside-in perspective - with the primary intention to source external ideas, technology and entrepreneurial culture (BioVentureHub, SynerLeap, Electrolux OI, Stena New Ventures, Stena Recycling Lab). Finally, two of the cases (TestaCenter and CampX), had from the start both a strong outside-in focus but simultaneously an inside-out intention. In the case of TestaCenter the inside-out intention concerns the interest in making its products well known among startups being trained at Testa Center towards industrializing, and in the case of CampX the external startups being invited come to an environment where they meet intrapreneurs and a substantial number of employees working in innovation projects together with external industry partners.

Interestingly, the majority of the outside-in cases enter into nonequity relations with the participating startups (BioVentureHub, SynerLeap , TestaCenter, Electrolux OI, CampX). Even the cases where investment resources are ready- available, it has not been put into the forefront, rather the focus has been on innovation collaboration through non-equity forms (Stena New Ventures and Stena Recycling Lab). The inside-out approaches are either integrating the new projects into existing business areas or consider equity-investment in spinouts.

Next, the findings from the empirical study will be presented below under the headings: rationale behind the initiative, overall objectives, and categories of metrics applied.

\section{Rationale behind the new initiative}

Each corporation had their own rationale behind the start of the new collaboration initiative. This in turn led to different set ups, or models. In several cases the original idea of a specific initiative came from individual employees who presented their ideas for corporate leaders and received their support to move on to design the specific initiative. Thus, the belief in the need of the new initiative and its objective(s), were anchored with the corporate leadership that decided to support the development of the initiative, for example in the cases of: Ericsson Garage, Ericsson One, Electrolux Open Innovation function, Stena Metall's New Ventures and Recycle Lab, and CampX. In the case of Ericsson Garage that originated in Stockholm, the continued diffusion of the initiative to other locations was based on local needs and local initiatives that coordinated both with the local site management 
and with the central Garage organization in Stockholm. CampX was an integrated part of a major CEO initiative for establishing collaboration with external competence, including startups. The Greenhouse case, on the other hand, was initiated by change agents within the $\mathrm{R} \& \mathrm{D}$ organization and was later included into the corporate strategy based on evidence from running two cycles of acceleration. However, in three cases where the government contributed with funding, BioVentureHub, SynerLeap and TestaCenter, the initiative came from strong change agents within the organizations. For the latter three, the funding from the government played a key role to start the unit for collaboration with startups.

Another important factor for the creation and development of each case was the inspiration and learning from each other through study visits, both on own initiatives and by taking part of common research projects on dyads (Steiber \& Alänge, 2020). These learning processes also led to clear differentiations between the models, e.g. in the case of Stena New Ventures and Ericsson Garage in different locations. This led in some cases to similar models but with very different objectives, e.g. in the cases of: BioVentureHub that aims for disruptive innovation outside of the core product areas of AstraZeneca and views itself as a growth catalyst for independent companies; and SynerLeap that invites startups with the ambition of creating collaboration projects inside $\mathrm{ABB}$ and providing support to explore funding possibilities through ABB Technology Ventures. Stena Metall, with its Stena New Ventures and Stena Recycling Lab, had clear objectives with its initiatives and by learning from other large corporations and their models, they could take components that fit well with their own objectives, but also disregard components that fit less well. This was specifically the case with companies joining a bit later and that learned from the other companies, starting early with corporate-startup collaboration initiatives. Another effect from the joint learning process was also that companies joining later could drastically speed up their process of designing and establishing their new initiative. This could partly be explained by the fact that the companies got, and still get, not only inspiration from one another, but also utilize experiences and formats/routines from the other companies to develop their own model faster.

Finally, depending on the specific context and needs of a corporation and the learning generated from running a specific model, changes were introduced in the practices on a dyad level. In some cases, this learning process resulted from a conscious revision of the original rationale and objectives, both on a corporate and a dyad level. Further evolution of the models has been taken place in all of the 10 empirical cases.

\section{Overall objectives}

The objectives expressed at a corporate level differ between the cases, but one common objective expressed in all cases is a need of establishing relationships to a community of startups and entrepreneurs in order to access new ideas and technology needed for the future development of the large corporation. In many cases it has also been expressed a need of changing the enterprise culture at the large firm by having direct contact with entrepreneurs and startups, and one objective in several cases was to become more innovative and agile. For example, SynerLeap has a very clear objective on speeding up innovation cycle time by working with multiple startups at the same time. BioVentureHub, TestaCenter and CampX, all emphasize the impact on knowledge transfer and new agile work processes. Several of the cases such as: BioVentureHub, TestaCenter, and the Greenhouse mentioned that their approach to support startup companies and external entrepreneurs was essential for strengthening the ecosystem or industry in which the large firm is part of, and thus by strengthening the ecosystem also strengthening the firm. Furthermore, the development of a talent pool for recruiting people with relevant knowledge was important for most of the cases, which also led some companies to cooperate with external providers, such as universities (TestaCenter) and other external providers of training programs (The Greenhouse). In some cases, the objective is also commercial, e.g. by educating startups in the large firm's equipment and methodologies, which later could lead to startups becoming new customers to the large firm.

\section{Categories of metrics applied}

In theory, the evaluation of a project should be conducted as a comparison between the obtained results at the end of the set project time and the objectives set at the start of the project - this is also based on an assumption that the objectives have been possible to follow-up and measured during, and at project closure. Looking into the empirical data, in most cases there were corporate objectives set from the start except in one case where the initiative was taken bottom-up and after showing some results, two year into the project, the corporate leadership were formally involved in establishing a revised set of objectives (Lantmännen).

In most cases there were no agreed upon ways to measure the attainment of objectives, i.e. there were no specific metrics. In the cases when metrics were set upfront from the corporate perspective, they focused on one or a few specific deliverables related to the objectives. For example, for Ericsson Garage Gothenburg: "Pitch 2 projects twice a year for Global Ericsson Garage in Stockholm" or for Ericsson One: "One new game changer per year with a 1-billion- dollar market potential."

As the objectives set on a corporate level typically did not include defined ways to measure the fulfillment of theme, qualitative reporting of activities became the norm for many of the cases. Indicators of activities were developed on the dyad level for internal follow-up and reflection on what was being accomplished and how it could be further improved. Typical activity indicators could concern attractiveness (no. of visitors; no. of applicants; utility of equipment), exploration (no. of startups in the hub, no. of internal ideas, no. of external ideas) or collaboration (no. of collaboration projects (e.g. at Stena New Ventures/Recycling Lab, SynerLeap, and Electrolux Open Innovation). 
In several cases the dyads constructed funnels to reach the ultimate outcome, such as Ericsson One (1000 ideas - 60 ideation projects - 10 MVP to test) or Stena New Ventures (100 good ideas - 5 developed ideas -3 tested - 1 launched). In other cases, it was an outspoken intention not to use traditional metrics and instead base the direction on a vision and broad objective, combined with a continual dialogue with the corporate level based on description of activities, collaborations generated, and innovations introduced (e.g. BioVentureHub, Ericsson Garage, CampX, and Electrolux Open Innovation).

For three of the cases that were started with government funding, BioVentureHub, SynerLeap and TestaCenter, the specific stakeholder perspective of the funding agency Vinnova, influenced the follow-up measurements due to demands on a regular reporting to Vinnova. For example, those cost directly related to public funding and outcomes in terms of support to development of external startups and entrepreneurs. However, also those follow- up reports were based on a dialogue, rather than hard core metrics.

A specific point that several of the interviewees mentioned was the impact of learning by running the model - over several cycles or years. As a result, new knowledge and insights were generated and some of the cases were characterized by in-depth reflection on the content which resulted in major changes (e.g. The Greenhouse and Electrolux Open Innovation). Also, for the BioVentureHub, the realization of future sector convergence resulted in a major change in the criteria for selecting companies to enter into the hub to co-locate, opening up for other technology areas than those traditionally related to pharmaceuticals. Further, also other insights led to the opening up of the environment for R\&D units for medium sized and larger companies (initially it was more early phase startups), and also to an increased focus on international companies (e.g. Ericsson One and SynerLeap, which for instance onboarded Indian startups in order to further strengthen the collaboration between the local startup ecosystem and $\mathrm{ABB}$ in India)).

These changes in focus and practices on a dyad level, called for revisions of dyads' objectives and metrics, and in some degree for corporate objectives and metrics. In addition, the programs with government funding, the changing priorities were being communicated and discussed with Vinnova that took the changes into consideration. Those changes are part of Vinnova's own learning process as the phenomenon of dyads is a rather new one (interview, June 2020) and will therefore lead to changes also in their follow ups of the hubs, e.g. at the final ex-post evaluation (after 10 years) of these programs.

\section{Discussion}

The trigger to establish the collaboration initiative came in some cases from the corporate leadership, and in some cases as a bottom up approach through an internal, strong change agent. In some of the latter, the funding from the government played an important role for the corporate decision to invest in the new initiative.

The empirical study proved clearly that the 'stakeholder dimension', as well as the 'performance dimension' played important roles in evaluating the collaboration initiative. In all cases, the large firm had initial objectives, or 'beliefs' behind the initiatives. There was a common belief that the initiative would positively affect the innovativeness of the large firm, either by having the large firm being approached to new ideas, technologies or even new business models, but also by getting a positive entrepreneurial spill-over effect to the large firm's own culture and way of doing. In addition, in some cases the belief was that it would be good also for the brand of the company or customer relations (see Table 2). Those beliefs, or in some cases objectives fit very well with what previous research has identified, presented in the theoretical context above. However, it also deviates to some extent from previous research as none of the 10 cases, not even those with a possibility to invest in the startups, seem to focus primarily on return on investment. This might be a result of the strong belief that the collaboration with startups was necessary for innovation, access to talents, etc. In regard to the dyads, objectives and metrics on a dyad-level also fit well with previous research as the 10 cases measured the growth of the 'collaboration unit', and later in some cases also the performance of the startups engaged in the program. Again, however, a deviation was identified, now in the form of 'economic results' of the unit. None of the cases mentioned this area as one that was measured. This might be explained by the same reason as used above for the corporation. 
Table 2: Performance metrics and a stakeholder perspective

\begin{tabular}{|c|c|c|}
\hline & Corporate & Dyad \\
\hline Knowledge/Learning & $\begin{array}{l}\text { On a Corporate level the most frequently mentioned } \\
\text { objectives were: } \\
\text { 1. Knowledge and learning from startups: about ne- } \\
\text { eds, new technology and the culture of working in an } \\
\text { entrepreneurial and agile way } \\
\text { 2.Training employees in a more entrepreneurial and } \\
\text { agile way of working. }\end{array}$ & $\begin{array}{l}\text { Dyads seldom received metrics related to corporate objectives. Ins- } \\
\text { tead, dyads developed objectives and metrics based on both the input } \\
\text { from corporate perspective and their own focus, for example: } \\
\text { 1. Internal focus: } \\
\text { - No. of internal people engaged - culture influence } \\
\text { - No. of R\&D people involved } \\
\text { - No of new technology areas represented among startups } \\
\text { - No. of startup projects with employees participating } \\
\text { - No. of internal ideas entered the program } \\
\text { No. of employees who know that you can come with your own idea } \\
\text { and start developing it. } \\
\text { 2. External focus: } \\
\text { - No. of visitors - attending seminars at the Dyad } \\
\text { No. of external startups connected to the Dyad }\end{array}$ \\
\hline Resources & $\begin{array}{l}\text { Developing a talent pool of qualified and entrepre- } \\
\text { neurial individuals } \\
\text { Creating collaboration opportunities } \\
\text { Identifying potential new suppliers of new technique } \\
\text { Create new growth business through disruptive in- } \\
\text { novation }\end{array}$ & $\begin{array}{l}\text { Dyads seldom received metrics related to the corporate objectives. } \\
\text { Dyads developed several resource measurements: } \\
\text { - } \quad \text { No. of startup collaborations } \\
\text { - No. of validated MVPs } \\
\text { - No. of startups that received internal interest } \\
\text { - No of startups that together with corporate's solutions reached market } \\
\text { No. of startups that became global technology provider to the corpo- } \\
\text { ration } \\
\text { - Investment (USD) in startups }\end{array}$ \\
\hline Other & $\begin{array}{l}\text { Attract young talent and make employees stay be- } \\
\text { cause the corporate is perceived as innovative work- } \\
\text { ing with startup - i.e. a direct effect on the brand. }\end{array}$ & $\begin{array}{l}\text { Only two cases focused on mobilizing ideas from the employees and used } \\
\text { clear metrics set by the corporate: } \\
\text { Examples on metric: } \\
\text { - "Pitch } 2 \text { projects twice a year" for central organization } \\
\text { - "One game changer per year with a one- billion- dollar market } \\
\text { - potential }\end{array}$ \\
\hline
\end{tabular}

Important to notice, however is that even if there were strong beliefs that the initiative would lead to positive effects for the larger firm, very few of the cases had metrics from the start. For example, on a dyad level, metrics was a focus area that commonly became more important over time in parallel with the dyads' own learning processes. As the dyad started to learn about what works and what works less well, both for the startups and for the large firm, the knowledge on what are valuable to measure and how to measure those things, increased. In general, though, metrics on a dyad level usually focused initially on 'process metrics', e.g. number of startups signed up to the dyad, and then over time transferred over to metrics that were measuring true value created (e.g. number of startups that were in development projects with the large firm), or value captured by both the startup and the large firm (e.g. no. of startups that have become global 
technology providers to the large firm). It was also identified to be important for the dyad to be measured on things that they actually could control. In this context, one of our interviewees commented from the dyad level: "it is important to measure what you can control although what is outside of control of the dyad at times also is being measured".

On a corporate level, metrics, other than very high level ones such as "one game changer per year with a one billion dollar market potential", usually didn't exist in the beginning (ex.ante). However, over time, as the firm learned how the new initiative could create value for the large firm, some of the cases established, or plan to establish corporate metrics (e.g. SynerLeap, CampX, Ericsson One, Stena Recycling Lab). One example on this could be number of startups that became 'global technology providers' to the large firm.

Regarding the third dimension, the 'time dimension', this dimension was trickier to test. While both the stakeholder and performance dimension were 'solid' in their value when discussing and categorizing metrics for the new initiative, the time dimension was a bit harder to use as metrics in most cases were not set ex-ante, and in some cases not even used in itinere. In addition, many of the cases, specifically the ones without government funding, did not have a certain frequency for ex-post evaluations. The cases that had clear ex-post evaluations were the cases funded by the government (BioVentureHub, SynerLeap and TestaCenter) as well as the cases in which the program was 'updated' into new versions at a certain frequency (The Greenhouse and Electrolux Open Innovation). For some more details from the empirical study, see table 3 below. However, the time dimension was still found to be valuable and therefore valid as it brought new insights on how established objectives and metrics, or thoughts on objectives and metrics, had evolved over time. This dimension supported in not only identifying the evolution of objectives and metrics but also to identify the triggers to why objectives and metrics had changed or are planned to be changed.

Table 3: Performance metrics and a temporal dimension

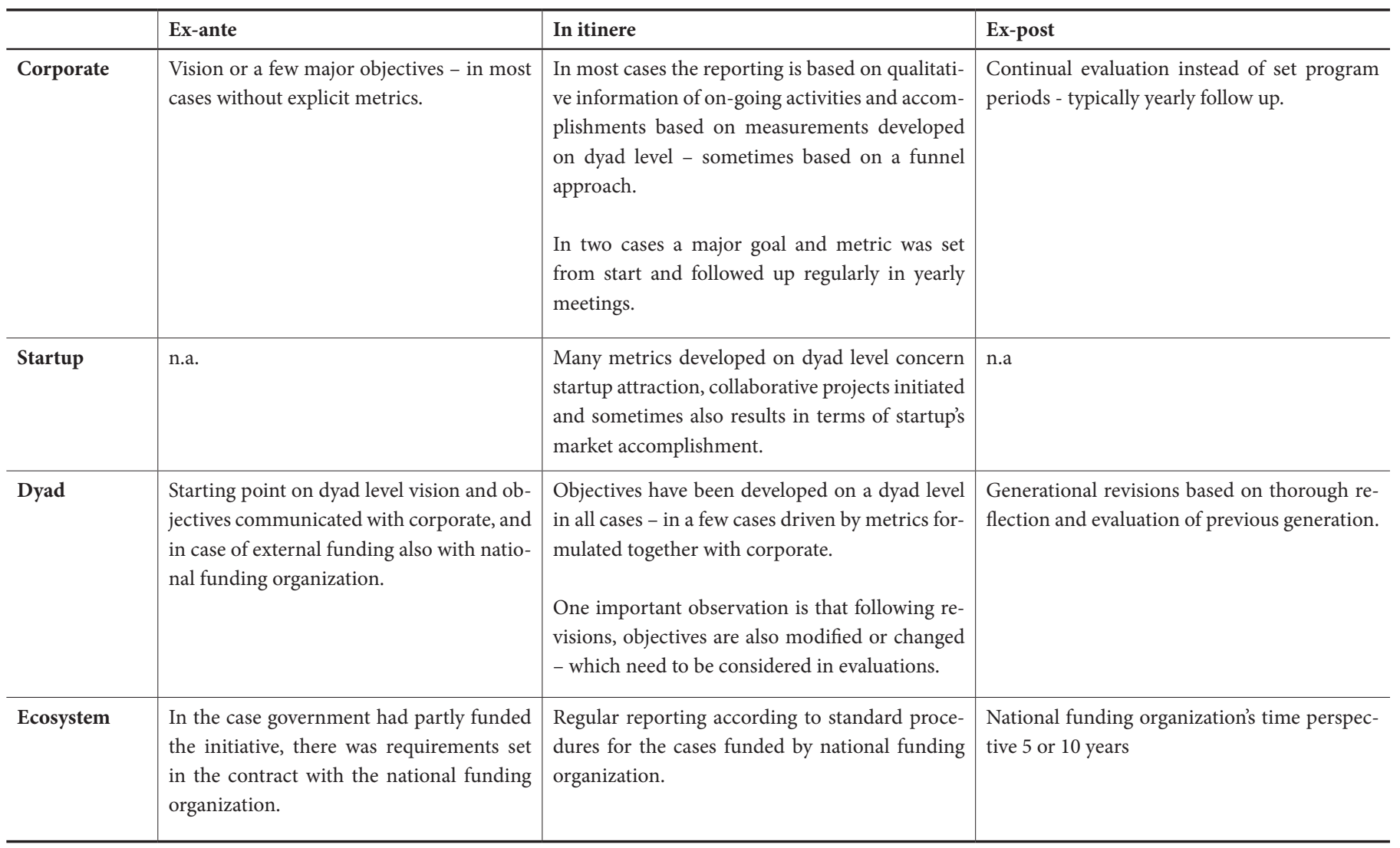

To sum up, in all cases there is a clear learning over time, both in the generational development cases (The Greenhouse and Electrolux Open Innovation) and the yearly evaluated cases (Ericsson Garage, Ericsson One, Stena New Ventures, Stena Recycling Lab, CampX), as well as in the cases with external Vinnova funding (BioVentureHub, SynerLeap, TestaCenter). This means that the ambition what to do and measure might change and that how to do and measure continuously is being improved and modified, which means that sometimes the changes go beyond or do not support the corporate goals from the outset - which indicates that an ex-post evaluation cannot simply start from the initial goals, but need to include the dynamic learning that has taken place during the on-going program. On dyad level, this is managed by modifying measurements that are used internally and communicated to the corporate leadership. However, also the three cases of external Vinnova funding consider changing priorities in their communication - which takes place both through 
the standard documented process - where the project leader continuously reports goal fulfilment and changes in stipulated progress reports and in the final report - and in dialogue meetings with Vinnova.

Based on the above, the empirical study does test the analytical evaluation framework and found both the framework and the three dimensions being valuable for planning, follow- up, evaluating, and comparing different corporate-startup collaboration models over time.

\section{Conclusions and implications}

The three-dimensions evaluation framework was found useful, based on the result from the empirical study of 10 cases of five totally different corporate-startup collaboration models.

Both the stakeholder- and the performance dimensions were found to be valuable in the discussion with the case companies. The time dimension was a bit harder to apply as many hadn't used this dimension themselves, or because the interviewee hadn't been part of the establishment of the new initiative. However, this dimension was still found to be valuable as it brought new insights on how objectives and metrics had evolved over time. Further, in most cases there was a clear learning over time, which means that the ambition what to do and measure might change and that how to do and measure continuously is being improved and modified. Sometimes the changes go beyond, or do not support the corporate goals from the outset - which indicates that an ex-post evaluation cannot simply start from the initial goals but need to include the dynamic learning that has taken place during the on-going program. On a dyad level, this is managed by modifying measurements that are used internally and communicated to the corporate leadership. The three cases with external government funding also consider changing priorities, and continuously report goal fulfilment and changes in the stipulated progress reports and in dialogue meetings with the government agency 'Vinnova'.

The implication for managers and researchers is of great importance. This paper indicates that the framework presented in this paper potentially could be the generic framework researchers have been looking for in order to measure the result, not only from different corporate-startup collaboration models in isolation, but also cross models. As a corporation usually has not only one of these eight models, but several, for example a corporate venture unit and a corporate accelerator program such as in the case of Disney and many other companies, a generic framework would be very valuable for these companies to measure the difference in results cross models.

Further, the three-dimensional framework could be used in planning, better understanding, and/or developing objectives and metrics for business managers staring up and heading up different corporatestartup collaboration initiatives. In addition, this paper has showed that both managers and researchers need to understand that objectives and metrics are a result of the dyad's and the large firm's own learning process over time, why those will change over time. It might therefore be natural to focus on process metrics at the start and then, over time, refine the metrics into metrics that measure true value creation and capturing. Objectives and metrics therefore need to be viewed from a more dynamic perspective. One way, however, to evolve faster in regard to metrics is to learn from other firms that are before the own firm on the learning curve.

\section{Limitations and future research}

The framework is including a multi-stakeholder perspective and that means that in order to conduct a thorough test of the framework, there is a need of data from all perspectives. A natural next step is therefore to test the framework from a startup, as well as from an ecosystem (e.g. government) perspective. Further, in the interviews with dyad level leaders, it was found that an additional important input into the dyad's own goal setting process are other corporatewide goals that were not initially included in the decision to start the program but were in some cases included when the program was in operation. For this reason, there is a value of testing this framework further by interviewing also top managers and critical internal decision-makers such as e.g. head of R\&D. This could further contribute to the understanding of the decision-making and evaluation process within large firms with corporate-startup collaboration initiatives ongoing.

Further, a specific issue needing consideration in future research is the meaning of ex post evaluation. The programs with funding from Vinnova have natural ex-post time perspectives of 5 years initial funding and a potential 5 years additional funding, which mean that there is a definite ex-post evaluation to be conducted after 10 years. This evaluation will then have two purposes; first, to provide an evaluation for the Vinnova funding and second, providing an evaluation to the large firm of the value of the dyad to the corporate in the future. In the other cases there were no definite ex-post time perspective - instead, two strategies were used: either a continual yearly reporting to the corporate leadership that could result in major revisions; or an approach based on reflection on dyad level, viewing the program in a generational development perspective, i.e. to make time for reflection with the intention of revising and improving the program.

\section{References}

Aggarwal, V. \& Kapoor, M. (2018), Innovation growth from knowledge transfer in international strategic alliances, Journal of Strategy and Management, 11(4), 483-496.

Bamford, J. and Ernst, D. (2002). Managing an alliance portfolio. The McKinsey Quarterly, 3(8), 25-35.

Bouncken, R.B., Clauss, T. \& Reuschl, A.J. (2016). Coworking-spaces in Asia: A Business Model Design Perspective. SMS. Hong Kong.

Cabral, V., \& van Winden, W. (2016). Coworking: an analysis of coworking strategies for interaction and innovation. International Journal of Knowledge-Based Development, 7(4), 357-377. 
Cabral, V. \& van Winden, W. (2018). The promise of coworking environments: a content analysis of the positioning of collaborative workspaces in Amsterdam. International Journal of Entrepreneurship and Small Business, 40(3), 399-423.

Chesbrough, H. \& Rosenbloom, R. (2002). The role of the business model in capturing value from innovation: evidence from Xerox Corporation's technology spin-off companies. Industrial and Corporate Change, 11(3), 529-555.

Chesbrough, H. (2003). Open innovation: The new imperative for creating and profiting from technology, Harvard Business School Press, Boston, MA.

Chow, W. \& Chan, L.S. (2008). Social network, social trust and shared goals in organizational knowledge sharing. Information \& Management, 45(7), 458-465.

Christensen, C.M. \& Overdorf, M. (2000). Meeting the challenge of disruptive change, Harvard Business Review, 78(2), 66-76.

Clauss, T. \& Spieth, P. (2017), Governance of open innovation networks with national vs international scope, Journal of Strategy and Management, 10(1), 66-85.

Cooke, P. (2002). Biotechnology Clusters as Regional, Sectoral Innovation Systems. International Regional Science Review, 25(1), 8-37.

Danneels, E. (2002), The dynamics of product innovation and firm competences, Strategic Management Journal, 23(12), 1095-1121.

Drori, I., \& Wright, M. (2018). Accelerators: Characteristics, trends and the new entrepreneurial ecosystem. In Accelerators. Edward Elgar Publishing.

Eisenhardt, K. M. \& Graebner, M. E. (2007), Theory building from cases: opportunities and challenges, Academy of Management Journal, $50(1), 25-32$.

Gallini, N. T. (2002). The Economics of Patents: Lessons from Recent U.S. Patent Reform. Journal of Economic Perspectives, 16(2), 131-154.

Gallivan, M (2008). Striking a balance between trust and control in a virtual organization: A content analysis of open source software case studies. Information Systems Journal, 11(4), 277-304.

Gertler, M.S. \& Levitte, Y.M. (2005). Local Nodes in Global Networks: The Geography of Knowledge Flows in Biotechnology Innovation. Industry and Innovation, 12(4), 487-507

Holste, J.S. \& Fields, D. (2010). Trust and tacit knowledge sharing and use. Journal of Knowledge Management, 14(1), 128-140.

Inkpen, A.C. \& Tsang, E.W.K (2005). Social capital, networks, and knowledge transfer. Academy of Management Review, 30(1), 146-165.
Irving, G.L., Ayoko, O.B. \& Ashkanasy, N.M. (2020). Collaboration, Physical Proximity and Serendipitous Encounters: Avoiding collaboration in a collaborative building. Organization Studies, 41(8), 1123-1146.

Lee, S.M., Olson, D.L. \& Trimi, S. (2012), Co-innovation: convergenomics, collaboration, and co-creation for organizational values, $\mathrm{Ma}$ nagement Decision, 50(5), 817-831.

Lemarié, S., Mangematin, V., \& Torre, A. (2001). Is the Creation and Development of Biotech SMEs Localised? Conclusions Drawn from the French Case. Small Business Economics, 17(1-2), 61-76.

March, J.G. (1991), Exploration and exploitation in organizational learning, Organization Science, 2(1), 71-87.

McKelvey, M, Alm, H., \& Riccaboni, M. (2003). Does co-location matter for formal knowledge collaboration in the Swedish biotechnology-pharmaceutical sector?. Research policy, 32(3), 483-501.

Muegge, S. 2013. Platforms, Communities, and Business Ecosystems: Lessons Learned about Technology Entrepreneurship in an Interconnected World. Technology Innovation Management Review, 3(2), 5-15.

Nagy, G. \& Lindsay, G. (2018). Why Companies Are Creating Their Own Coworking Spaces. Harvard Business Review, 24.

Nambisan, S. (2017), Digital entrepreneurship: Toward a digital technology perspective of entrepreneurship, Entrepreneurship Theory and Practice, 41(6), 1029-1055.

Nonaka, I. (1994). A dynamic theory of organizational knowledge creation. Organization Science, 5(1), 14-37.

Oukil, M. S. (2011), A development perspective of technology-based entrepreneurship in the Middle East and North Africa, Annals of Innovation \& Entrepreneurship, 2(1), 1-13.

Porter, K., Whittington, K. B., \& Powell, W. W. (2005). The institutional embeddedness of high-tech regions: relational foundations of the Boston biotechnology community. Clusters, networks, and innovation, 261, 296.

Robinson, D, Rip, A., \& Mangematin, V. (2007). Technological Agglomeration and the emergence of clusters and networks in nanotechnology. Research Policy, 36(6), 871-879.

Romero, D. \& Molina, A. (2011). Collaborative networked organisations and customer communities: value co-creation and co-innovation in the networking era. Production Planning \& Control, 22(5-6), 447-472

Rogers, E. M., \& Roger, G. (1983). DIFFUSION OF INNOVATIONS $3 R D E R E V$. New York: Free Press; London: Collier Macmillan.

Roth, A., Dumbach, M., Schliffka, B. \& Möslein, K. (2017), Successful management of diverse corporate innovation communities, Journal of Strategy and Management, 10(1), 2-18. 
Simard, C., \& West, J. (2006). Knowledge networks and the geographic locus of innovation. Open innovation: researching a new paradigm, 220-240.

Song, M., Berends, H., Van Der Bij, H., \& Weggeman, M. (2007). The effect of IT and co-location on knowledge dissemination, The Journal of product innovation management, 24(1), 52-68.

Steiber, A. \& Sverker Alänge (2020). Corporate-startup Co-creation for Increased Innovation and Societal Change. Triple Helix, 1.aop (2020), 1-23.

Steiber, A. (2020). Technology Management: Corporate-Startup CoLocation and How to Measure the Effects. Journal of Technology Management \& Innovation, 15(2), 11-22.

Stuart, T. \& Sorenson, O. (2003). The geography of opportunity: Spatial heterogeneity in founding rates and the performance of biotechnology firms, Research Policy, 32(2), 229- 253.

Teece, D. (1986). Profiting from technological innovation: Implications for integration, collaboration, licensing and public policy, Research Policy, 15(6), 285-305

Teece, D., (1986a). Transaction cost economics and the multinational enterprise, Journal of Economic Behavior and Organization, 7(1), 21-45
Teece, D., (1989). Interorganizational requirements of the innovation process. Managerial and Decision Economics, 10(1), 35-42.

Valkokari, K., Seppänen, M., Mäntylä, M., \& Jylhä-Ollila, S. (2017). Orchestrating innovation ecosystems: A qualitative analysis of ecosystem positioning strategies. Technology Innovation Management Review, 7(3).

Vanhaverbeke, W. (2006). The interorganizational context of open innovation. Open innovation: Researching a new paradigm, 205-219.

Weiblen, T. \& Chesbrough, H.W. (2015), Engaging with startups to enhance corporate innovation, California Management Review, 57(2), 66-90.

Yeung, H.W-C., Liu, W. \& Dicken, P. (2006). Transnational Corporations and Network Effects of a local manufacturing cluster in mobile telecommunications equipment in China. World Development, 34(3), 520-540.

Zenun, M. M. N., Loureiro, G., \& Araujo, C. S. (2007). The Effects of Teams' Co-location on Project Performance. In Complex systems concurrent engineering (pp. 717-726). Springer, London. 
